\title{
Synthesis of solketal over zirconia based acid catalysts
}

\author{
S. S. Reena ${ }^{1,2}$, S. Z. M. Shamshuddin ${ }^{1,2 *}$, V. T. Vasantha and J. Q. D'Souza ${ }^{1,3}$ \\ ${ }^{1}$ Chemistry Research Laboratory, HMS Institute of Technology, NH4, Kyathasandra, Tumakuru, Karnataka, India \\ ${ }^{2}$ Research and Development Center, Bharathiar University, Coimbatore, Tamil Nadu, India \\ ${ }^{3}$ Department of Chemistry, St. Josephs' College, Langford Road, Bengaluru, Karnataka, India
}

Received: 22 March 2018

Revised: 06 May 2018

Accepted: 23 May 2018

DOI: https://doi.org/10.3329/bjsir.v54i1.40728

\begin{abstract}
Microwave assisted synthesis of 'solketal' over zirconia $\left(\mathrm{ZrO}_{2}\right)$ and its modified forms $\left(\mathrm{Mo}(\mathrm{VI}) / \mathrm{ZrO}_{2}, \mathrm{~W}(\mathrm{VI}) / \mathrm{ZrO}_{2}\right.$ and $\mathrm{V}(\mathrm{V}) / \mathrm{ZrO}_{2}$ ) coated on honeycomb monoliths is reported. The solid acids were coated on honeycomb monoliths by 'dip and dry' method and characterized for their surface acidity, crystalinity, functionality, morphology and elemental analysis by using techniques such as $\mathrm{NH}_{3}$-Temperature programmed desorption $\left(\mathrm{NH}_{3}-\mathrm{TPD}\right)$, powder X-ray diffraction (PXRD), Fourier transform-infrared spectroscopy (FTIR), Scanning electron microscopy (SEM) and Inductively coupled plasma-optical emission spectroscopy (ICP-OES). The honeycomb monoliths coated with solid acids were employed as catalysts in the condensation of glycerol with acetone to synthesize solketal under microwave irradiation conditions. The reaction conditions such as molar ratio of the reactants (glycerol: acetone), reaction temperature, reaction time were studied to obtain highest possible yield of solketal with greater selectivity. The catalytic activity of honeycomb catalytic material was compared with the powder forms of the catalysts. $98 \%$ yield of solketal with $98 \%$ selectivity was achieved over $\mathrm{Mo}(\mathrm{VI}) / \mathrm{ZrO}_{2}$ coated on a honeycomb monolith in a very shorter reaction time of $8 \mathrm{~min}$ at $60{ }^{\circ} \mathrm{C}$ under microwave heating. These honeycomb catalytic material were found to be easily reactivable and reusable atleast for 6 reaction cycles. Hence, honeycomb catalysts were found to be efficient, economical and effective in the synthesis of value added chemical such as solketal. A possible mechanism for the formation of solketal is proposed.
\end{abstract}

Keywords: Solketal; Honeycomb monolith; Modified zirconia; Microwave

\section{Introduction}

Cordierite $\left(2 \mathrm{Al}_{2} \mathrm{O}_{3} \cdot 2 \mathrm{MgO} .5 \mathrm{SiO}_{2}\right)$ honeycomb monoliths (HMs) play a vital role in heterogeneous catalysis as catalyst carriers. HMs coated with active catalysts are generally employed in gas phase reactions such as, automotive emission control systems as a catalytic converters in diesel and gasoline engines, ozone abatement in aircrafts and selective reduction of $\mathrm{NO}_{\mathrm{x}}$ (Nijhuis et al., 2001). But their role in fine chemical synthesis is very narrow.

Some of the advantages of HM-catalytic material over powder form of catalysts are: small amount of the active catalyst coated on a HM in the form of a thin layer is more effective and result in high surface active sites, easy separation and complete recovery from the reaction mixture, tolerate a wide range of reaction temperatures, safe to store, long life time and environmentally safe disposal, etc (Nijhuis et al., 2001). These advantages are least applicable when the catalysts are in powder form.

Zirconia and its cation/ anion modified forms have played an important role as catalysts in a wide range of organic transformations such as isomerization, esterification, transesterification, etc., leading to the formation of industrially important fine chemicals. Especially, zirconia modified with $\mathrm{SO}_{4}{ }^{2-}, \mathrm{Mo}(\mathrm{VI}), \mathrm{W}(\mathrm{VI}), \mathrm{V}(\mathrm{V})$ etc., have proved to result in the formation of 'super acid' sites over zirconia (Reddy and Patil, 2009).

'Solketal' (1,2-isopropylidene glycerol) is a condensation product of glycerol and acetone. It is used as an additive to reduce particulate emission and enhance cold flow properties of liquid transportation fuels (Pariente et al., 2008). 
When added to gasoline, it decreases gum formation and increases octane number. Solketal can also be used as a solvent and plasticizer in polymer industry and as a solubilising, suspending agent in pharmaceutical industries (Pariente et al., 2008). Importance is given towards the synthesis of solketal so that glycerol which is a by-product during biodiesel synthesis could be converted into a value-added chemical, i.e., solketal. Conventionally, it was being prepared using homogenous acid catalysts such as $\mathrm{HCl}, \mathrm{H}_{2} \mathrm{SO}_{4}$ and $\mathrm{H}_{3} \mathrm{PO}_{4}$ (Krief et al., 1998). Keeping in view the disadvantages associated with homogenous and corrosive liquid acids, efforts have been made to replace them with eco-friendly heterogenous solid acids such as clays, zeolites, etc (Nanda et al., 2016; Priya et al., 2017; Manjunathan et al., 2015).

Microwave-assisted organic transformations accelerate reactions from hours to minutes and minutes to seconds. Microwave-assisted organic transformations have advantages over conventional heating methods such as: provide quick results by drastically reducing reaction times, uniform heating occurs throughout the material, high efficiency of heating, increases product yield with high purity of the product by reducing undesirable side reactions and environmental heat is avoided (Hayes et al, 2002).

In the present article, work done on the synthesis, characterization and catalytic activity studies (in solketal synthesis) of honeycomb monoliths (HMs) coated with solid acids such as $\left(\mathrm{ZrO}_{2}, \mathrm{Mo}(\mathrm{VI}) / \mathrm{ZrO}_{2}, \mathrm{~W}(\mathrm{VI}) / \mathrm{ZrO}_{2}\right.$ and $\mathrm{V}(\mathrm{V}) / \mathrm{ZrO}_{2}$ ) is reported. The solid acids were coated on HMs and characterized for their properties such as surface acidity, crystalinity, functionality, morphology and elemental analysis by suing suitable analytical techniques. The HM-catalytic material were then analyzed for their catalytic activity in the microwave assisted condensation of reaction of glycerol with acetone to synthesize industrially important product i.e., solketal. The reaction conditions were optimized to obtain highest possible yield of solketal with good selectivity. The activities of HM-catalytic material were compared with their powder forms. Reactivation and reusability of HM-catalytic material was also studied.

\section{Materials and methods}

Cordierite honeycomb monoliths were procured from Shreya Ceramics, Baroda, India. The raw materials such as zirconyl nitrate, ammonium molybdate, ammonium tungstate, ammonium metavanadate, glycerol and acetone were obtained from LOBA Chemie Ltd, India.

\section{Preparation of catalytic materials}

The bare HMs were coated with solid acids such as $\mathrm{ZrO}_{2}$, $5 \% \mathrm{Mo}(\mathrm{VI}) / \mathrm{ZrO}_{2}, 5 \% \mathrm{~W}(\mathrm{VI}) / \mathrm{ZrO}_{2}$ and $5 \% \mathrm{~V}(\mathrm{~V}) / \mathrm{ZrO}_{2}$ by 'dip and dry' procedure (Shyamsundar and Shamshuddin, 2018).

Typically, zirconia $\left(\mathrm{ZrO}_{2}\right)$ was coated on a $\mathrm{HM}$ by using a dilute solution prepared by using known amount of zirconyl nitrate and deionized water. The resulting solution was coated on a HM by dipping and drying in a muffle furnace preheated at $400{ }^{\circ} \mathrm{C}$. The dip and dry steps were repeated for 6 to 8 times until $\sim 0.02 \mathrm{~g}$ of the active catalyst $\left(\mathrm{ZrO}_{2}\right)$ is coated on the HM.

Similarly, $\sim 0.02 \mathrm{~g}$ of $5 \% \mathrm{Mo}(\mathrm{VI}) / \mathrm{ZrO}_{2}$ or $5 \% \mathrm{~W}(\mathrm{VI}) / \mathrm{ZrO}_{2}$ or $5 \% \mathrm{~V}(\mathrm{~V}) / \mathrm{ZrO}_{2}$ were coated on $\mathrm{HMs}$ by using dilute solutions consisting of known amounts of zirconyl nitrate and ammonium molybdate/ ammonium tungstate.

Powder forms of the catalysts $\left(\mathrm{ZrO}_{2}, 5 \% \mathrm{Mo}(\mathrm{VI}) / \mathrm{ZrO}_{2}\right.$, $5 \% \mathrm{~W}(\mathrm{VI}) / \mathrm{ZrO}_{2}$ and $5 \% \mathrm{~V}(\mathrm{~V}) / \mathrm{ZrO}_{2}$ ) were also prepared by impregnation method. The resulting catalytic materials were abbreviated as HM-Z, HM-MZ, HM-WZ and HM-VZ for honeycomb forms and Z-P, MZ-P, WZ-P and VZ-P for powder forms.

The catalytic materials (both HM coated and powder forms) were calcinated at $550{ }^{\circ} \mathrm{C}$ for $5 \mathrm{~h}$ before their characterization and using them as catalytic material in the synthesis of solketal.

\section{Characterization of the catalytic materials}

Surface acidity and acid site distribution was determined by $\mathrm{NH}_{3}$-TPD method by using Mayura-TPD instrument. PXRD patterns were obtained from Seimens-D5005 X-ray diffractometer with a Ni filtered $\mathrm{Cu}-\mathrm{K} \alpha$ radiation $(1.5418 \AA$ ). The FT-IR spectra were recorded on Nicolet instrument by $\mathrm{KBr}$ pellet technique. The SEM images were obtained from JEOL JXA-8530F microscope. ICP-OES elemental analysis of $\mathrm{MZ}, \mathrm{WZ}$ and VZ catalyst samples was analyzed over Thermo-iCAP 6000 instrument.

\section{Catalytic activity evaluation (in solketal synthesis)}

Microwave assisted synthesis of solketal was carried out in Labmatrix Microwave Reactor (LM-MWS-31) via condensation of known quantities of glycerol $(20 \mathrm{mmol})$ with acetone $(15 \mathrm{mmol}$ ) by using $\sim 0.02 \mathrm{~g}$ of the catalysts (either HM-coated or powder forms). The reactions were carried out in a specially designed glass reactor (suitable for HM catalytic material) attached with a water cooled condenser. The reaction mixture was heated for a particular time and 
temperature $\left(60{ }^{\circ} \mathrm{C}\right)$ and then cooled to room temperature. The catalytic material was separated from the reaction mixture and was analysed quantitatively using GC (Mayura) gas chromatograph fitted with TR-Wax capillary column attached to flame ionisation detector. The reaction mixture was also qualitatively analysed with GC-MS (Varian) and two products were observed. The cyclic acetal products 5-membered cyclic ketal (1,2-isopropylidene glycerol) commercially called as solketal as a major product and 6-membered cyclic ketal (2,2-dimethyl-1,3-dioxan-5-ol) called dioxane as a minor product along with the by-product water were observed (Scheme 1). Reactions were carried out with powder form of the catalysts using the similar method as described above. For comparison

$$
\begin{aligned}
& \text { Yield of solketal }(\%)=\frac{[\text { solketal }]}{[\text { solketal }]+[\text { dioxane }]+[\text { glycerol }]} \times 100 \\
& \text { Yield of solketal }(\%)=\frac{[\text { dioxane }]}{[\text { solketal }]+[\text { dioxane }]+[\text { glycerol }]} \times 100
\end{aligned}
$$

reactions were also carried out using conventional method on a hot plate cum magnetic stirrer.

The yield (\%) of the products (solketal or dioxane) was calculated by using the following formulae:

\section{Results and discussion}

\section{Characterization of catalytic materials}

Surface acidity by $\mathrm{NH}_{3}-\mathrm{TPD}$

The acid site distribution and total surface acidity (TSA) values of the prepared catalytic materials are listed in Table I and they found to follow the order: $\mathrm{Z}<\mathrm{WZ}<\mathrm{VZ}<\mathrm{MZ}$. Pure zirconia $(Z)$ has lowest acidity, but upon incorporation of cations $(\mathrm{Mo} / \mathrm{W} / \mathrm{V})$ strong influence on the surface acidity of zirconia was observed which may be through synergistic effect arouse because of the coordination number of the inserted cation maintained in the host oxide lattice i.e., (Mo/W/V) ions loaded in to the $\mathrm{Zr}^{4+}$ lattice, positive charge imbalance occurs. As a result acid sites are generated. Further, it is observed that pure Z has 'weak and moderate' acids sites, whereas modified forms of $\mathrm{Z}$ (i.e., MZ/WZ/VZ) have 'moderate, strong' and traces of 'very strong' acid sites (Reddy and Patil, 2009).

\section{Crystalinity by PXRD}

The PXRD patterns of Z, MZ, WZ and VZ (HC coated) are shown in Fig. 1. Pure $Z$ show reflection pertaining to both monoclinic (M) and tetragonal $(\mathrm{T})$ phases. Whereas, modified forms of zirconia (i.e., MZ/WZ/VZ) show reflections due to only tetragonal phase of zirconia. Transformation from monoclinic to catalytically active tetragonal phase in case of modified forms of zirconia can be attributed to the strong influence of cations $(\mathrm{Mo} / \mathrm{W} / \mathrm{V})$ on zirconia (Reddy and Patil, 2009). In the PXRD patterns of $\mathrm{MZ} / \mathrm{WZ} / \mathrm{VZ}$ no reflections related to $\mathrm{MoO}_{\mathrm{x}}, \mathrm{WO}_{\mathrm{x},} \mathrm{VO}_{\mathrm{x}}$ are observed indication that these cations are satisfactorily incorporated with zirconia. Further, in the PXRD patterns of HC-catalytic material, no reflections pertaining to bare HM are seen indicating the effectiveness of the method followed to coat the catalyst on the HM.

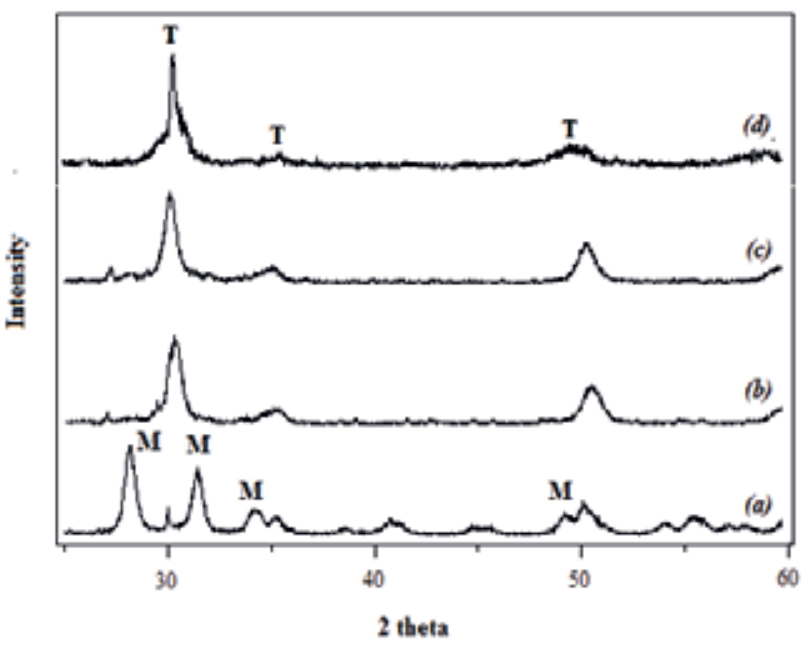

Fig. 1. PXRD patterns of (a) Z, (b) MZ (c) WZ and (d) VZ. $[\mathbf{M}=$ Monoclinic; $\mathbf{T}=$ Tetragonal $]$.

Table I. Acid site distribution, TSA and \% of metal in catalytic materials used in the present study

\begin{tabular}{cccccc}
\hline & \multicolumn{5}{c}{ Acid site distribution $(\mathrm{mmol} / \mathrm{g})$} \\
Catalytic material & Weak & Medium & Strong & Very strong & TSA \\
Z & 0.03 & 0.38 & - & - & 0.41 \\
MZ & - & 0.09 & 0.90 & 0.05 & 1.04 \\
WZ & - & 0.07 & 0.75 & 0.10 & 0.92 \\
VZ & - & 0.10 & 0.78 & 0.07 & 0.95 \\
\hline
\end{tabular}


Functionality by FT-IR

The FTIR spectra of the catalytic material used for the present work are presented in Fig. 2. The bands at $\sim 1391 \mathrm{~cm}^{-1}$ and $\sim 1118 \mathrm{~cm}^{-1}$ can be due to $\mathrm{Zr}-\mathrm{OH}$ bending and $\mathrm{Zr}-\mathrm{O}-\mathrm{Zr}$ stretching modes respectively, which confirms the formation of $\mathrm{ZrO}_{2}$ phases. The broad bands in all the catalyst samples at $\sim 3400 \mathrm{~cm}^{-1}$ and $\sim 1646 \mathrm{~cm}^{-1}$ are due to stretching mode of $-\mathrm{OH}$

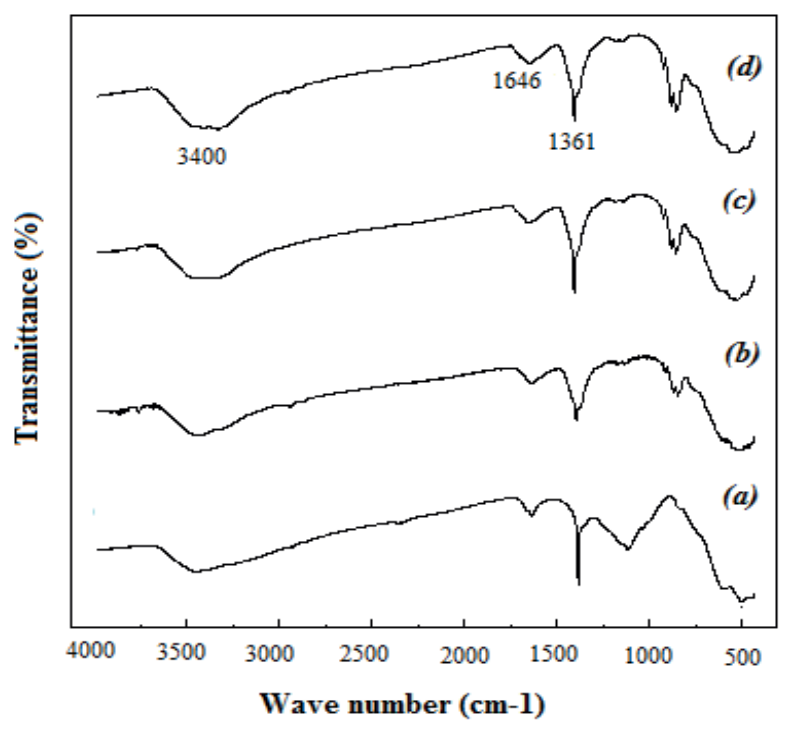

Fig. 2. FT-IR spectra of (a) Z, (b) MZ (c) WZ and (d) VZ. with hydrogen bonding and vibrations of acidic $-\mathrm{OH}$ and respectively (Sohn et al., 2003). The band at $3400 \mathrm{~cm}^{-1}$ helps in the generation of Bronsted acidic sites. In case of $\mathrm{MZ} / \mathrm{WZ} / \mathrm{VZ}$ samples the peak at $\sim 848 \mathrm{~cm}^{-1}$ is due to M-O-M ( $\mathrm{M}-$ metal ion) stretching mode of vibration for $\mathrm{MO}_{\mathrm{x}}$ (Chary et al., 2004). This indicates that $\mathrm{MO}_{\mathrm{x}}$ is strongly dispersed on the surface of $\mathrm{ZrO}_{2}$ wherein peak at $\sim 1118 \mathrm{~cm}^{-1}$ (Fig. 2a) gets disappeared.

\section{Morphology by SEM}

SEM images of all the prepared HM-catalytic material are shown in Fig. 3. The pictures show scale like images which indicate an almost uniform, adherent and a strong coating of the active catalyst on the surface of HC. This indicates that the method used to coat the active catalyst on a bare $\mathrm{HC}$ is suitable enough to obtain an efficient coating.

\section{Elemental analysis by ICP-OES}

The results obtained from ICP-OES indicates that the modified forms of zirconia i.e. $\mathrm{MZ}, \mathrm{WZ} \& \mathrm{VZ}$ consisted of $5.02 \% \mathrm{Mo}(\mathrm{VI}), 4.98 \% \mathrm{~W}(\mathrm{VI})$ and $5.03 \% \mathrm{~V}(\mathrm{~V})$ respectively.

\section{Catalytic activity evaluation (in solketal synthesis)}

The condensation reactions of glycerol with acetone were carried out over all the catalytic materials (both HM-coated as well as powder forms) and the results are given in Table II. Interestingly, a correlation between the surface acidity and

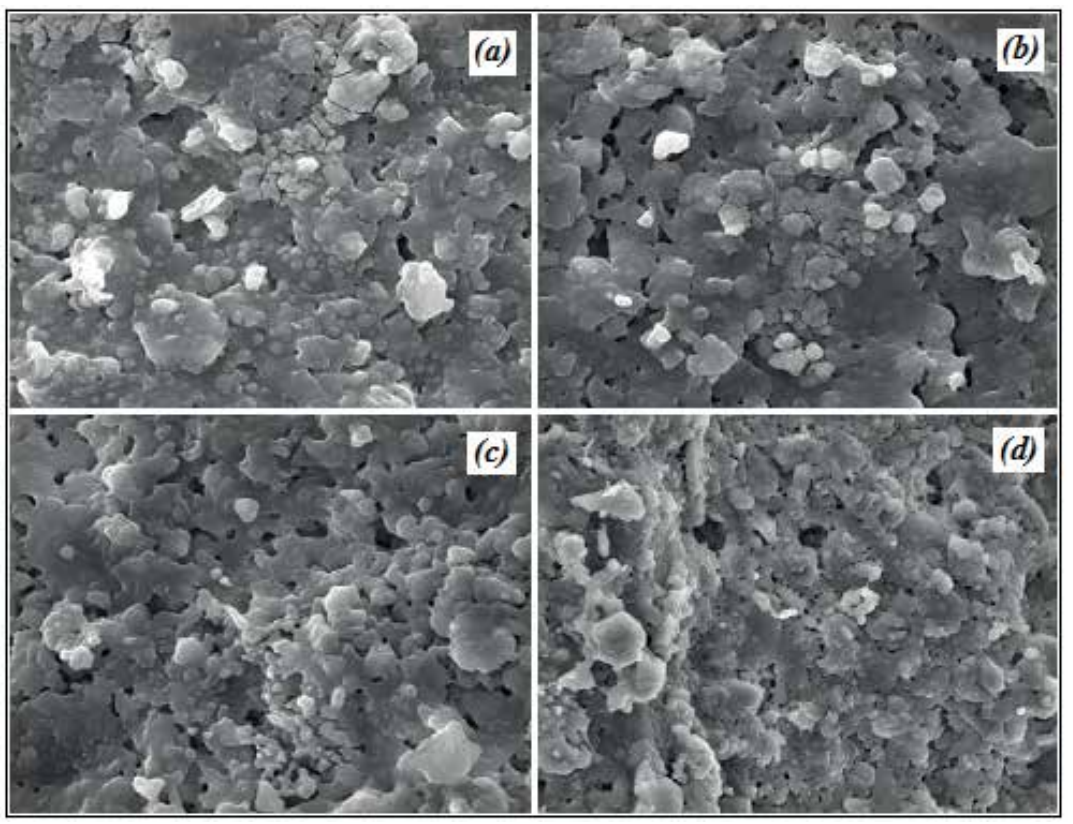

Fig. 3. SEM pictures of (a) Z, (b) MZ (c) WZ and (d) VZ. [Magnification $=2000 x$; Resolution $=10 \mu \mathrm{m}$ ]. 
the catalytic activity of the catalytic materials was observed. The catalytic activity was found to follow the order: $\mathrm{Z}<\mathrm{WZ}$ $<\mathrm{VZ}<\mathrm{MZ}$. This order is similar to the order of their acidity. When the condensation reaction was carried out in the absence of any catalyst, only $07 \%$ conversion of glycerol with $100 \%$ selectivity towards solketal was observed.

Zirconia being least acidic was less activity in the condensation reaction whereas MZ being highly acidic bear highest activity in the reaction. Even though the major product of the reaction is solketal, dioxane was also formed as the minor product. The selectivity towards either solketal or dioxane was found to correlate with the acid strength of the catalytic material. Pure zirconia which has weak and moderate acid sites produced only solketal and it is $100 \%$ selective. But over modified forms of zirconia (MZ/WZ/VZ), the conversion of glycerol as well as the yield (\%) of solketal was high. This indicates that the formation of solketal requires 'moderate and strong' acid sites. However, over modified forms of zirconia (MZ/WZ/VZ), dioxane was also formed to a small extent (2-8\%). Formation of dioxane can be attributed to the presence of very strong acid sites over modified forms of zirconia. Over MZ catalyst the yield of dioxane is least (i.e., $2 \%$ ) and over WZ the yield was found to be $8 \%$. Comparatively, MZ catalyst was found to be suitable for the selectivity synthesis of solketal in good yields because it showed good conversion of glycerol $(98 \%)$ with good selectivity (98\%) towards the formation of the desired product i.e., solketal.

When the reactions were carried out over powder forms, even though same amount of the catalyst $(0.02 \mathrm{~g})$ was used the conversion of glycerol was found to be lesser than that of HC-catalysts. Moreover powder forms of the catalysts were found to face difficulty during separation from the reaction mixture. Therefore, for further optimisation studies HM-MZ was selected as the catalytic material.

Table II. Catalytic activity of Z, MZ, WZ and VZ in the synthesis of solketal

\begin{tabular}{lccc}
\hline Catalytic & & $\begin{array}{c}\text { Yield of } \\
\text { material }\end{array}$ & $\begin{array}{c}\text { Yield of } \\
\text { glycerol (\%) } \\
\text { solketal (\%) } \\
\text { dioxane (\%) }\end{array}$ \\
HM -Z & $46(12)$ & 100 & 00 \\
HM -MZ & $98(18)$ & 98 & 02 \\
HM -WZ & $99(20)$ & 92 & 08 \\
HM-VZ & $97(17)$ & 94 & 06 \\
Z-P & $28(08)$ & 100 & 00 \\
MZ-P & $64(14)$ & 98 & 02 \\
WZ-P & $69(14)$ & 92 & 08 \\
VZ-P & $66(15)$ & 94 & 06 \\
\hline
\end{tabular}

Further, for the purpose of comparison, reactions were also carried in conventional heating method and the results are shown in Table II (Column 2). The conversion of glycerol was found to be very low when compared to microwave heating method. Whereas the yield of either solketal or dioxane remained almost the same irrespective of the heating method.

\section{Effect of molar ratio of the reactants}

The effect of molar ratio of reactants on the conversion (\%) of glycerol and selectivity towards solketal or dioxane was studied by varying the molar ratio of glycerol to acetone from 1:1 to 1:8 using HM-MZ catalytic material (Fig. 4). An increase in the conversion of glycerol was observed with an increase in the molar ratio (glycerol: acetone) from 1:1 to 1:6

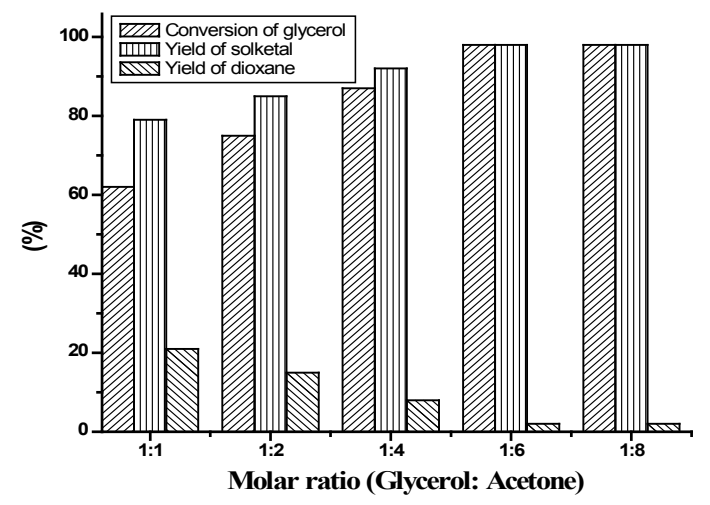

Fig. 4. Effect of molar ratio of the reactants on the conversion of glycerol and yield of products over HM-MZ catalytic material.

[Reaction conditions: Reaction time $=8 \mathrm{~min}$; reaction temperature $=60^{\circ} \mathrm{C}$, amount of catalyst $=0.02 \mathrm{~g}$ ].

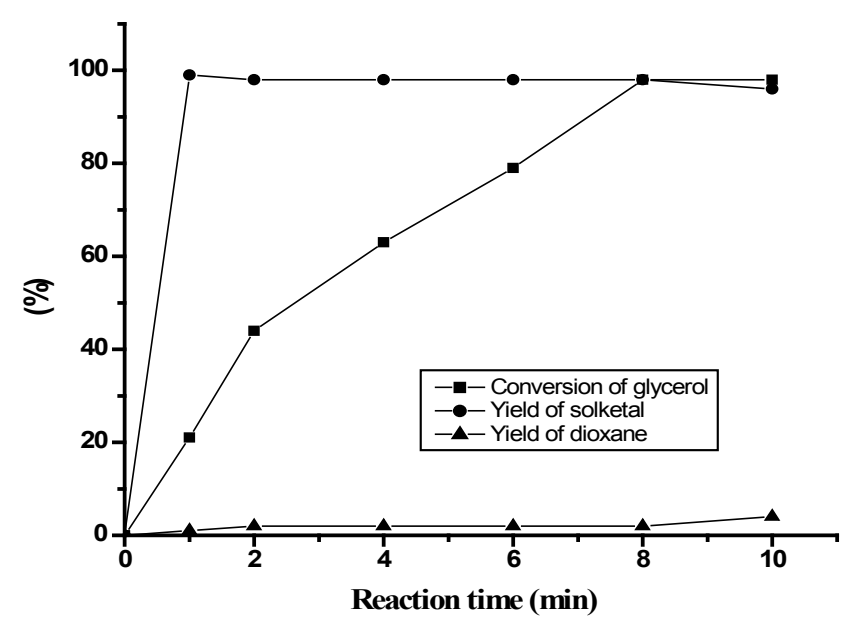

Fig. 5. Effect of reaction time on the conversion of glycerol and yield of products over HM-MZ catalytic material.

[Reaction conditions: Molar ratio (glycerol: acetone) $=1: 6$; reaction temperature $=60 \mathrm{oC}$, amount of catalyst $=0.02 \mathrm{~g}$ ]. 
due to an increase in the accessibility of acetone with glycerol. An excess of acetone used in this reaction favoured the forward reaction and improved the complete conversion of glycerol (Melero et al., 2010). Further increase in the molar ratio beyond 1:6 did not result in a reasonable increase in the conversion of glycerol. However, selectivity towards either solketal or dioxane did not affect with molar ratio.

\section{Effect of reaction time}

The reaction time of microwave irradiation was varied from 1 min to $10 \mathrm{~min}$ and the results are shown in Fig. 5. The conversion of glycerol increases with reaction time till $8 \mathrm{~min}$

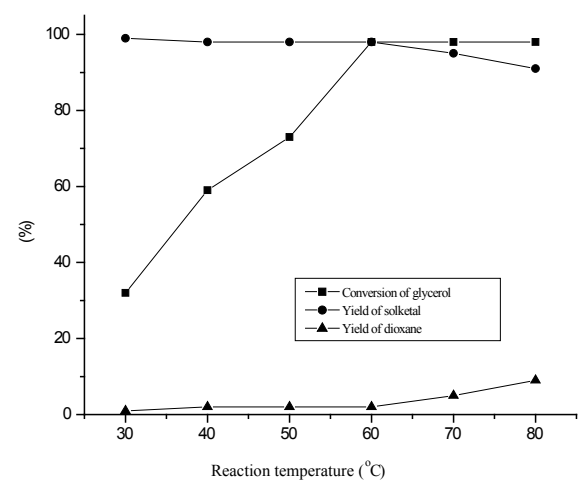

Fig. 6. Effect of reaction temperature on the conversion of glycerol and yield of products over HM-MZ catalytic material.

[Reaction conditions: Molar ratio (glycerol: acetone) $=1: 6$; reaction time $=8 \mathrm{~min}$; amount of catalyst $=0.02 \mathrm{~g}]$.

and then levels off beyond 8 min. A maximum conversion of glycerol (98\%) with a yield of solketal (98\%) was observed at a reaction time of just $8 \mathrm{~min}$. Even though the conversion of glycerol did not change with reaction time beyond $8 \mathrm{~min}$, the selectivity towards solketal was found to decrease with an increase in the selectivity towards dioxane (4\%). It may be due to an internal rearrangement of 6-membered (dioxane) product to 5-membered (solketal).

\section{Effect of reaction temperature}

Effect of reaction temperature was studied by varying the temperature from $30{ }^{\circ} \mathrm{C}$ to $80{ }^{\circ} \mathrm{C}$ over $\mathrm{HM}-\mathrm{MZ}$ catalytic material and the results are shown in Figure 6. An increase in the conversion of glycerol was observed with an increase in the reaction temperature. The conversion of glycerol increased till the reaction temperature of $60^{\circ} \mathrm{C}$ and then levels off. However, at higher reaction temperature beyond $60{ }^{\circ} \mathrm{C}$ the selectivity towards the desired product i.e., solketal was found to decrease with an increase in the selectivity towards dioxane. This indicates that high reaction temperature favors the formation of 6 membered dioxane.

\section{Effect of reactivation and reusability of the catalytic material}

The MZ (both HM and powder forms) catalytic material, after the first reaction cycle was reactivated by washed with acetone and dried in a hot air oven at $120^{\circ} \mathrm{C}$ for $1 \mathrm{~h}$ and calcined at $550^{\circ} \mathrm{C}$ for $1 \mathrm{~h}$. Thus reactivated catalytic material was re-used in the next reaction cycle. Such cycles were conducted for up to 6 times and the results are given in Table III. Interestingly, no change in the conversion of glycerol or selectivity towards the products was observed when the reactions were carried out over HM-MZ catalytic material. This also indicates that there is no leaching of the active catalyst form the HM. But over powder form of the catalyst (MZ-P) a gradual decrease in the conversion of glycerol was observed. This decrease can be attributed to the loss of the powder catalyst during separation from the reaction mixture. While separating the catalyst from the reaction mixture via filtration, some amount of the catalyst may be lost which sticks to the surface of the filter paper. Further loss of the powder catalyst while removing from the reaction flask also cannot be ruled out. This type of loss or leaching may not occur when used in the honeycomb coated form. This fact indicates that the catalysts coated on honeycomb monoliths are much more economical and efficient as they can be easily separated from the reaction mixture without any loss of the catalyst, easily reactivated and effectively can be recycled

Table III. Reusability of MZ catalytic material (both HM and powder forms) in the condensation reaction of glycerol with acetone

\begin{tabular}{ccccccc}
\hline Catalytic material & \multicolumn{7}{c}{ Conversion (\%) of glycerol / Reaction cycle (No.) } \\
& 1 & 2 & 3 & 4 & 5 & 6 \\
HM-MZ & 98 & 98 & 98 & 98 & 98 & 98 \\
MZ-P & 64 & 61 & 56 & 52 & 46 & 41 \\
\hline
\end{tabular}

[Reaction conditions: Molar ratio (glycerol: acetone) $=1: 6$; reaction time $=8 \mathrm{~min}$; reaction temperature $=60^{\circ} \mathrm{C}$, amount of catalyst $=0.02 \mathrm{~g}$ ] 
Table IV. Comparative catalytic activity of the catalysts reported in the literature in the synthesis of solketal

\begin{tabular}{lcc}
\hline \multicolumn{1}{c}{ Catalytic material } & $\begin{array}{r}\text { Conversion of } \\
\text { glycerol (\%) }\end{array}$ & $\begin{array}{r}\text { Yield of } \\
\text { solketal (\%) }\end{array}$ \\
H- $\beta$ (Manjunath et al, 2015) & $86(65 \mathrm{~min})$ & 98 \\
SZ (Vasantha et al, 2018) & $96(100 \mathrm{~min})$ & 94 \\
Mordenite (Samudrala et al, 2017) & $95(15 \mathrm{~min})$ & 98 \\
Amberlyst-35 (Nanda et al, 2016) & $90(20 \mathrm{~min})$ & 97 \\
HM -MZ (present work) & $98(8 \mathrm{~min})$ & 98 \\
\hline
\end{tabular}

when compared to their powder forms. However, no change in the selectivity of either product (solketal or dioxane) was observed.
Recently, we have reported the synthesis of solketal over sulfated zirconia, which took longer reaction times of 100 min (Vasantha et al., 2018). Mordenite and Amberlyst-35 have also been used as catalytic material (Priya et al., 2017; Nanda et al., 2016) and were active in the synthesis of solketal but showed marginal deactivation with time. Comparatively, the catalytic material i.e., honeycomb monolith coated with solid acid such as $\mathrm{Mo}(\mathrm{VI}) / \mathrm{ZrO}_{2}$ used in the present study was found to be very efficient in producing solketal in a very low reaction time of $8 \mathrm{~min}$ with low catalyst loading of $0.02 \mathrm{~g}$. Generally, the catalytic material coated on honeycomb monoliths used for the present work were less expensive, efficient as well as eco-friendly in nature with complete recovery, easily separable from the reaction mixture and recyclable with negligible loss of the activity.

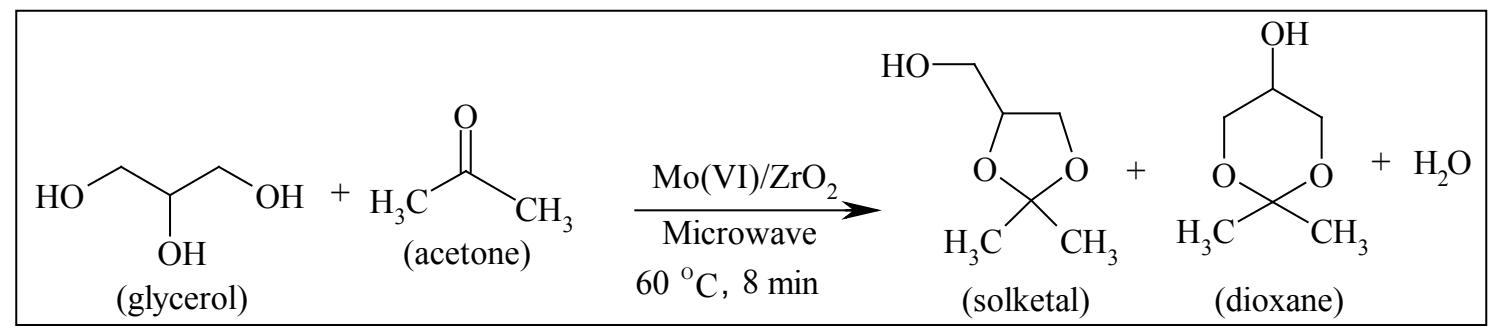

Scheme 1. Catalytic synthesis of solketal via condensation of glycerol and acetone over zirconia based solid acid.

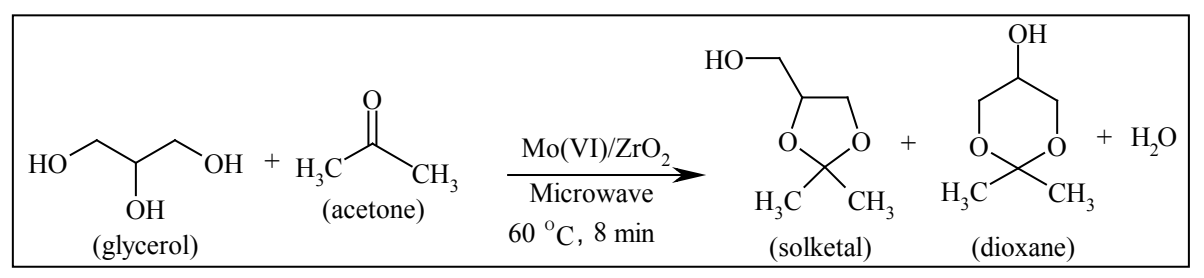

Acid catalyzed condensation reaction of glycerol with acetone over HM-coated with $\mathrm{Mo}(\mathrm{VI}) / \mathrm{ZrO} 2$ under microwave irradiation.

Comparison of the catalytic activity of other catalysts in the synthesis of solketal from the literature survey

The catalytic activity of the catalysts used for the present work was compared with the activity of the catalytic materials reported in the literature (Table IV). The catalysts reported have their own merits and limitations even though they reflect higher conversion, as per industrial practice, more selectivity of the desired product also plays an important role. Zeolite $H-\beta$, even though showed good selectivity but conversion was relatively low (Manjunath et al, 2015).

\section{Mechanism of formation of solketal}

The acid catalysed condensation of glycerol with acetone involved 3 steps (Scheme 2). The first step is the surface reaction between the adsorbed acetone and glycerol over the acid catalyst surface $\left(\mathrm{H}^{+}\right)$to form the acetal. The next step is the removal of water leading to the formation of a carbocation and the last step is the removal of a proton $\left(\mathrm{H}^{+}\right)$to form solketal (Nanda et al, 2014). 


\section{Conclusion}

Condensation reaction of glycerol with acetone was effectively carried out over modified forms of zirconia coated on honeycomb monoliths via microwave irradiation. The method was efficient, quick, ecofriendly and safe. Industrially important organic compound (solketal) was synthesised in good yields with high selectivity over honeycomb monolith coated with $\mathrm{Mo}(\mathrm{VI}) / \mathrm{ZrO}_{2}$ catalyst in a very short time of $8 \mathrm{~min}$ at 60 ${ }^{\circ} \mathrm{C}$. The honeycomb catalyst could be easily separated from the reaction mixture and reused which makes the method even more economical, ecofriendly and safe. Utilisation of honeycomb as catalyst carriers and microwave heating technique in the synthesis of organic fine chemicals is a very good initiative in the field of heterogenous catalysis.

\section{Acknowledgements}

Authors are grateful to VGST, Government of Karnataka (GRD-375/2014-15) for the part-financial support. The authors are thankful to the authorities of St. Joseph's College, Bangalore for PXRD and FTIR analysis. The authors are also grateful to IISc authorities for SEM and GC-MS analysis.

\section{References}

Chary KVR, Reddy KR, Kishan G, Niemantsverdriet JW and Mestl G (2004), Structure and catalytic properties of molybdenum oxide catalysts supported on zirconia, $J$. Catal. 226(2): 283-291. DOI:org/10.1016/j.jcat. 2004.04.028

Hayes BL (2002), Microwave synthesis: Chemistry at the speed of light, CEM Publishing: Matthews NC, USA.

Krief A, Provins L and Froidbise A (1998), Diastereoselective synthesis of dimethyl cyclopropane-1,1-dicarboxylates from a $\gamma$-alkoxy-alkylidene malonate and sulfur and phosphorus alylides, Tetrahedron Lett. 39(11): 1437-1440. DOI:org/ 10.1016/ S0040- 4039 (97) 10822-X

Manjunathan P, Sanjeev PM, Halgeri AB and Ganapati VS (2015), Room temperature synthesis of solketal from acetalization of glycerol with acetone: Effect of crystallite size and the role of acidity of beta zeolite. $J$. Mol. Catal. A. 396: 47-54. DOI:org/10.1016/j.molcata. 2014.09.028
Melero JA, Vicente G, Morales G, Paniagua $M$ and Bustamante J (2010), Acid-catalyzed etherification of bio-glycerol and isobutylene over sulfonic mesostructured silicas, Fuel. 89: 2011-2018.

Shyamsundar M and Shamshuddin SZM (2018), Effective synthesis of n-butyl salicylate over wash coated cordierite honeycomb by zirconia and mixed oxides: a kinetic study, Bangladesh J Sci. Indus. Res. 53(1): 63-76. DOI:org/10.3329/bjsir.v53i1.35912

Nanda MR, Yongsheng Zhang, Zhongshun Yuan and Chunbao Xu (2016), Catalytic conversion of glycerol for sustainable production of solketal as a fuel additive: A review, Renewable and Sustainable Energy Reviews 56: 1022-1031.

Nanda MR, Zhongshun Yuan and Chunbao Xu (2014), Selective Hydrogenolysis of Glycerol and Crude Glycerol (a By-Product or Waste Stream from the Biodiesel Industry) to 1,2-Propanediol over $\mathrm{B}_{2} \mathrm{O}_{3}$ Promoted $\mathrm{Cu} / \mathrm{Al}_{2} \mathrm{O}_{3}$ Catalysts, Fuel. 117: 470-484.

Nijhuis TA, Kreutzer MT, Romijn ACJ, Kapteijn F and Moulijn JA (2001), Monolithic Catalysts as More Efficient Three-Phase Reactors, Chem Engg Sci. 56(3): 823-829. DOI:org/10.1016/S0920-5861(00)00621-0

Pariente S, Tanchoux N and Fajula F (2008), Etherification of glycerol with ethanol over solid acid catalysts, Green Chem 11(8): 1256-1261.

Priya SS, Selvakannan PR, Chary KVR, Lakshmikantam M and Suresh KB (2017), Solvent-free microwave-assisted synthesis of solketal from glycerol using transition metal ions promoted mordenite solid acid catalysts, Molecular Catalysis. 434: 184-193. DOI:org/10.1016/j.mcat.2017.03.001

Reddy BM and Patil MK (2009), Organic syntheses and transformations catalyzed by sulfated zirconia, Chem. Rev. 109(6): 2185-2208.

Sohn JR, Chun EW and Pae Y I (2003), Effect of $\mathrm{V}_{2} \mathrm{O}_{5}$ Modification in $\mathrm{V}_{2} \mathrm{O}_{5} / \mathrm{TiO}_{2}-\mathrm{ZrO}_{2}$ Catalysts on Their Surface Properties and Catalytic Activities for Acid Catalysis, Bull. Korean Chem. Soc. 24(12): 1785-1793. DOI: org/10.5012/bkcs.2007.28.12.2459

Vasantha VT, Venkatesha NJ, Shamshuddin SZM, D'Souza JQ and Vijayasimhareddy BG (2018), Sulphated Zirconia Supported on Cordierite Honeycomb Monolith for Effective Synthesis of Solketal from Acetalisation of Glycerol with Acetone, Chemistry Select 3: 602-611. DOI:org/10.1002/slct.201702186 